\title{
A REPRESENTAÇÃO DE QUEM? PARTIDOS E OLIGARQUIAS NO NORDESTE
}

\author{
José Marciano Monteiro ${ }^{1}$ \\ Ednailson de Morais Júnior ${ }^{2}$
}

\begin{abstract}
Resumo: Após mais de duas décadas de Ditadura Militar, o Brasil passara pelo processo de reestabelecimento de um regime democrático. A Constituição de 1988 estruturou o sistema presidencialista representativo, caracterizando uma abertura política com um arranjo que, em tese, organizaria sistematicamente, de maneira responsável, as disputas políticas nos anos seguintes. Entretanto, do fim do Regime Militar até a primeira eleição direta para Presidente da República, houve um ambiente de disputas significativas no campo político, econômico e social que permitem a problematização sob as circunstâncias do processo de transição. Na região Nordeste, apesar de certo grau de institucionalização dos partidos, a presença de longos ciclos políticos e continuidade de tradicionais oligarquias permaneceu como característica de seus subsistemas eleitorais. Deste modo, pretendemos discorrer sobre a transição política em um contexto de domínio político de oligarquias e suas influências neste processo. Nesse sentido, realizaremos um estudo exploratório descritivo sobre os quadros dos principais partidos políticos na redemocratização: o PFL e o PMDB na região Nordeste, com o intuito de expor de maneira sintética, a relação entre partido e representação quando este é aparelhado em detrimento de uma elite regional e sua reprodução.
\end{abstract}

Palavras Chave: Partidos. Representação. Nordeste.

\section{REPRESENTATION FROM WHO? POLITICAL PARTIES AND OLIGARCHIES IN BRAZILIAN NORTHEAST REGION}

\begin{abstract}
After more than two decades of military dictatorship, Brazil had gone through the process of reestablishing a democratic regime. The 1988 Brazilian Constitution structured the representative presidential system, characterizing a political opening with an arrangement that, in theory, would systematically organize political disputes in the following years. However, from the end of the Military Regime to the first direct election for President of the Republic, there was an environment of significant political, economic and social disputes that allowed the problematization under the circumstances of the transition process. In the Northeast Brazilian region, despite a certain degree of party institutionalization, the presence of long political cycles and continuity of traditional oligarchies remained as characteristic of their electoral subsystems. Thus, we intend to discuss the political transition in a context of political dominance of oligarchies and their influences on this process. In this sense, we will carry out a descriptive exploratory study on the chart of the main political parties in the redemocratization: the PFL and the PMDB in the Northeast, in order to expose, in a synthetic way, the relationship between political party and representation when it is equipped to the detriment of a regional elite and their reproduction.
\end{abstract}

Keywords: Political parties. Representation. Brazilian Northeast

\footnotetext{
${ }^{1}$ Professor de Sociologia da Universidade Federal de Campina Grande - PB. Coordenador do Núcleo de Estudos sobre Elites, Famílias e Desigualdades - NEFADE/UFCG. Doutor. jm.monteiro17@gmail.com

${ }^{2}$ Pesquisador do Núcleo de Estudos sobre Elites, Famílias e Desigualdades - NEFADE/UFCG. Foi bolsista PIBIC/CNPq. Graduando em Licenciatura de Ciências Sociais CDSA/UFCGA. juninho.morais.sertania@gmail.com
} 
Revista NEP - Núcleo de Estudos Paranaenses, Curitiba, v. 5, n. 2, dez. 2019

\section{Introdução}

Nas Democracias representativas ${ }^{3}$ os partidos servem por excelência como o aparelho responsável pela organização sistemática do conjunto de elementos relativos a determinadas posições, valores e princípios de dados segmentos da sociedade, sendo, portanto, de sua responsabilidade recrutar os pretensos representantes para as disputas dentro do campo político em uma disputa pelo poder de legitimação, de instituir, de fazer crê e reconhecer como tal os agentes selecionados. (BOURDIEU, 1989)

No Brasil, após o término do período da ditadura militar, novamente passaríamos por um momento de retomatada da democracia. Em 1985, teríamos a realização das eleições presidenciais de forma indireta que culminou na eleição da chapa de Tancredo Neves e José Sarney, representantes dos dois partidos que despontavam como os principais na agenda política de retomada da democracia: o Partido da Frente Liberal (PFL), e o Partido do Movimento Democrático Brasileiro (PMDB) que, naquele contexto, fundaram a "Aliança Democrática ${ }^{4 "}$ alocando, em tese, as principais lideranças políticas do país na luta pela retomada de um governo civil.

No entanto, o contexto que permeou a redemocratização foi ambiente de tensão política, econômica e social (CODATO, 2005). O processo de retomada da democracia foi liderado por antigos representantes da classe política, alocados nos anos de ditadura ou na Aliança Renovadora Nacional (ARENA) ou no Movimento Democrático Brasileiro (MDB). Não houve, portanto, uma mudança significativa nas lideranças políticas naquele contexto. Por efeito, a constituição de 1988, significativa no que tange a promoção de direitos civis, políticos e sociais, não modificou profundamente a estrutura política e os processos eleitorais, convergindo elementos liberalizantes próprios de uma democracia

\footnotetext{
${ }^{3}$ A categorização de democracia representativa utilizada hegemonicamente na literatura neoinstitucional é a de Schumpeter (1984), que afirma que o método democrático é um acordo institucionalizado para se chegar ao poder de decisões políticas por meio de lutas competitivas em busca do voto da população. Alicerçada a isto, a ideia sobre representação pode ser subsidiada pelo trabalho de Castiglione e Warren (2006) que enfatizam que a representação é, por excelência, um modo simples de medir igualdade política e que a relação entre representante e representado deve ser responsável com o representante tendo a obrigação de "prestar contas" aos seus representados. (MACHADO 2016)

${ }^{4}$ A aliança democrática foi o movimento político realizado entre dissidentes do Partido Democrático Social (PDS) que formaram a Frente Liberal e aliaram-se ao PMDB para mobilizar parte da classe política e a sociedade civil para retomada do regime democrático. Cf: http://www.fgv.br/cpdoc/acervo/dicionarios/verbete-tematico/alianca-democratica
} 
representativa em seu aspecto formal, com velhos arcaísmos que remetem ao próprio período ditatorial e até da era varguista.

O sistema partidário foi elaborado de maneira que não conseguiu assegurar disciplina e fidelidade partidária e uma atuação clara das legendas sobre seus programas e ideologias, fazendo da representação política um objeto mal-acabado, tornando-se um entrave à consolidação democrática (KINZO 2001; NOVAES 1994; RODRIGUES 2009). Mais que isso, o forte personalismo ${ }^{5}$ da política tradicional no período antes e durante o autoritarismo institucionalizado no país permaneceu e continuou a se reproduzir em outra configuração de institucionalização e organização das disputas eleitorais em torno da representação que se deu com a redemocratização, num contínuo tradiçãomodernidade.

Diante de tal pressuposto, o presente trabalho tem por objetivo refletir sobre a problemática da representação partidária no contexto de retomada da democracia e sua relação com elites políticas regionais representantes da classe dirigente da região Nordeste. Para tanto, a análise se realizará, tendo como base a abordagem historiográfica e sociológica, discorrendo de forma descritiva e exploratória sobre a atuação de tradicionais famílias ${ }^{6}$ e seus representantes que comandavam a arena política na Região no período de redemocratização pós-ditadura nos dois principais partidos daquele contexto: PFL e o PMDB. Discorreremos, ainda, sobre o aparelhamento dos partidos, em detrimento da perpetuação e reprodução do poder e domínio destas oligarquias sobre o povo e o território nordestino; e como estes foram decisivos no pacto liberal-conservador que reestabeleceu o regime democrático e possibilitou uma nova dinâmica à política local e as formas de dominação desta classe dirigente ${ }^{7}$ sobre este território e sua nova configuração.

\footnotetext{
${ }^{5}$ Os estudos sobre identificação partidária no Brasil apontam o fenômeno do personalismo político como uma forma correspondente à falta de institucionalização político-patidária. Trata-se, portanto, de uma ligação populista entre o líder e os agentes sem mediação de parâmetros institucionalizados que precedem uma forma de dominação carismática. Cf com (CARREIRÃO e KINZO, 2004, p.131)

${ }^{6} \mathrm{O}$ levantamento de dados sobre as famílias e seus representantes consiste, essencialmente, da consulta ao banco de verbetes biográficos do Centro de Pesquisa e Documentação de História Contemporânea do Brasil (CPDOC/FGV) e dos trabalhos utilizados como referência.

${ }^{7}$ A Categoria de classe dirigente ou de classe política é empregada segundo a concepção de Gaetano Mosca, entendida minimante como a classe dos que governam e gozam dos privilégios da posição de monopólio do poder de decidir politicamente. Cf: (PERISSINOTTO, 2009, p.10)
} 


\section{Considerações sobre a formação Social do Nordeste}

A noção de territorialidade e região é fundamentada por práticas discursivas que subsidiam ao senso comum uma visão estigmatizada sobre a região legitimada por um discurso de autoridade (doxa) situada em um campo de disputa (BOURDIEU, 1989). A formação social do Nordeste é marcada pela forte presença de elites locais e pela dominação agrária. Conforme destaca Bernardes (2007), a imagem social do Nordeste se confunde com arcaísmos que remetem ao período de trabalho escravo e poder dos senhores de engenhos; da dominação dos coronéis; das histórias sobre o cangaço e das lideranças messiânicas, entre outras narrativas que conotam essas manifestações como uma resposta a um ambiente hostil em detrimento de condições climáticas e de constituição geográfica não favorável.

Há o estigma, portanto, de uma região que confunde arcaísmos com relações sociais atrasadas produzidas pela dominação material de uma população fundamentalmente agrária, sobre um território seco e atrasado economicamente, reforçado por uma literatura que pouco discorre sobre os impactos sofridos pela população nordestina no que tange ao desenvolvimento econômico de outras regiões, como ocorreu com a corrente migratória promovida pela produção de borracha no Norte amazônico que culminou em um declínio da mão de obra na região que não foi abastecida pela imigração europeia, por exemplo ${ }^{8}$.

Após o declínio da economia açucareira o Nordeste deixa ser o centro da economia do país e passa a ter como principal atividade a pecuária e a produção de algodão. Contudo, os longos períodos de estiagem característicos do semiárido foi uma preocupação posta pelo então presidente Epitácio Pessoa em resposta as manifestações das elites locais (BERNARDES 2007). Sendo, neste contexto, que, em 1919, o Nordeste ganha essa denominação oficialmente como região estratégica para o combate ao fenômeno da seca. Todavia, Monteiro (2017) destaca o ambiente de disputas dos mandatários locais pelas obras promovidas pelo poder público.

O processo de açudagem realizado no governo Epitácio Pessoa e, posteriormente, apropriado por José Américo no Nordeste, no "combate as secas", reforçava a concentração de poder das oligarquias, que, com este, reforçava-se por meio das obras de açudagem. Os "coronéis", além de concentrarem as melhores terras, passaram a concentrar também a

\footnotetext{
${ }^{8}$ Cf. FURTADO, 2004.
} 
água. Os açudes eram, em sua grande maioria, construídos pelo Estado nas terras dos coronéis. (Idem, p. 51)

Cabe também destacar que, com o declínio da economia do açúcar e do fluxo de migração, os coronéis sobressaíram como os líderes políticos da região, fundamentando uma forma de dominação política que caracterizaria a região até meados dos anos de 1950, reforçando no imaginário sobre o Nordeste de lugar do atraso político e econômico (VASCONCELOS, 2017).

Todavia, com projeto nacional de desenvolvimento dos militares e a modernização conservadora proposta por eles, as medidas de combate a seca pela $\operatorname{SUDENE}^{9}$ e, posteriormente, com o reordenamento do aparelho burocrático do Estado e a retomada da democracia em um ambiente de institucionalização das regras de competição político eleitoral, permeou-se no imaginário a construção e consolidação da modernização do Nordeste, uma modernização conservadora que, em grande medida, foi conduzida no plano nacional pela classe dominante e no plano regional articulada pela classe dirigente regional, herdeiras das tradicionais famílias oligárquicas da região.

Observa-se, assim, que, dificilmente, se compreenderá o Nordeste, enquanto região, sem que se lance o olhar para as relações de poder constituídas; sem que se compreenda a força que exercem as oligarquias ${ }^{10}$ locais e regionais na dinâmica de permanência ou mesmo de transformações das instituições no Nordeste brasileiro.

\section{Redemocratização: Partidos e Representação pós-Ditadura.}

Codato (2005) ao analisar os processos que caracterizaram a transição política da Ditadura à Democracia representativa instituída com a Constituição de 1988, afirma que não houve uma ruptura de um regime para o outro, mas uma mudança política deliberadamente construída pela coalizão de forças entre as Forças Armadas e representantes da sociedade civil representada por velhas elites políticas alocadas em algum dos partidos no sistema bi-partidário do período ditatorial. Kinzo (2001) expõe que os militares tiveram controle de todo processo de transição e, mesmo com a abertura e a

\footnotetext{
${ }^{9}$ A Superintendência do Desenvolvimento do Nordeste foi criada pela Lei $\mathrm{n}^{\circ}$ 3.692/1959 como um mecanismo de intervenção ao desenvolvimento da região. Disponível em: https://cpdoc.fgv.br/producao/dossies/JK/artigos/Economia/Sudene

${ }^{10}$ A categoria de oligarquias utilizada é a definição clássica nos estudos de elites tal qual posta por Robert Michels, ou seja, uma minoria que exerce o poder real dentro de uma organização. (PERISSINOTTO, 2009, p. 40)
} 
volta de um governo civil, os militares conservaram posições estratégicas no aparelho estatal e conservaram na nova Constituição, dispositivos que remetem a uma continuidade de elementos próprios do período autoritário.

No que tange os estudos sobre partidos políticos, alguns autores ao observarem o caso brasileiro, classificam nosso sistema partidário como "subdesenvolvido". Rodrigues (2009) evidenciou que as principais criticas inferidas envolvem a fragilidade pressuposta por uma baixa institucionalização dos partidos políticos, associada a uma baixa fidelidade, a fragilidade do conteúdo ideológico-programático e a um alto índice de migração partidária que sugere a problematização sobre a coesão e o funcionamento das legendas.

Neste contexto, cabe tratar sobre os aspectos que envolvem a constituição das coligações e alianças entre os partidos. Mainwaring e Lifian (1998) citados por Rodrigues (2009), entre outras observações, constataram e classificaram os partidos brasileiros como pouco comprometidos com a representação ideológica e com a institucionalização das legendas.

A política na região Nordeste, por exemplo, durante muito tempo, foi predominada pelo personalismo político (CARREIRÃO e KINZO, 2004). Isto é, os líderes políticos eram - em relação aos eleitores - muito maiores que os partidos, ou melhor, eram eles os próprios partidos. Antes, durante e depois da ditadura, salve algumas exceções, era comum que as oligarquias que integravam a classe dirigente do Nordeste se aliassem a base governista independentemente de que ideologia representasse. Muitas, aliás, alcançaram ou barganharam o poder político ao apoiarem os militares na consolidação do golpe de 1964 como, por exemplo, a oligarquia liderada por José Sarney que viria a se tornar presidente da República pela Aliança Democrática com a morte de seu companheiro de chapa Tancredo Neves.

Monteiro (2017) destaca como a aliança democrática, com o protagonismo do PMDB, em acordo com a grande elite midiática, reverberou um discurso em defesa da democracia, legitimando o pacto conservador que caracterizou a transição. O capital político, adquirido por meio destas estratégias, foi a chave para a reprodução das oligarquias políticas que compõem a classe dirigente nordestina, aliado a prática e estruturas de poder fundamentadas no nepotismo, já que se abrira um novo momento à representação, tornando o PFL e o PMDB em instâncias ou mesmo lugares da 
"sobrevivência". Mudaram-se as regras, o ambiente de disputa e os discursos, permaneceram os agentes ${ }^{11}$.

Nesse sentido, observar a representação partidária a partir da composição social dos partidos, as respectivas posições sociais dos agentes, suas profissões, suas formas de ingresso na vida política e, principalmente, sua origem social, torna-se imprescindível à compreensão dos fenômenos eleitorais de uma dada região por uma perspectiva para além das regras formalmente instituídas do sistema de representação política, pois, a partir disto podemos problematizar sobre quem de fato está sendo representado.

Portanto, na sequencia, ver-se-á de que forma o recrutamento, nas duas principais legendas, se transforma em espaço legitimado para a permanência, diante das transformações ocorridas, das velhas oligarquias nordestinas, ou seja, foi "preciso modificar para que permaneça como está". Assim, se verá como os dois principais partidos, durante o processo de retomada da democracia, permanecerá sendo controlado pelas tradicionais famílias. Famílias estas que compõem a classe dirigente nordestina, expondo características de reprodução, a partir do sistema partidário e do sistema eleitoral.

\section{PMDB e PFL: o novo, o velho e a representação no Nordeste.}

Como já fora destacado anteriormente, o processo de abertura democrática não foi promovida por uma ruptura do regime autoritário, mas a gradual liberalização do sistema eleitoral (KINZO 2001), permeada por um discurso de promoção da liberdade em seus aspectos social e econômico além do político. Destaca-se, também, como o PMDB e o PFL foram essenciais na consolidação deste pacto conservador pelo alto entre militares e civis na transição em busca deste suposto novo projeto de sociedade.

Contudo, ao observar os processos e acontecimentos políticos e sociais que marcariam a transição, em tese, PMDB e PFL, representariam a continuidade dos agentes políticos situadas na arena política durante os anos de ditadura e do bi-partidarismo. $\mathrm{O}$ PMDB fora a continuidade do MDB que em tese representava a oposição ao regime dos militares, enquanto que o PFL fora criado da dissidência de alguns membros do PDS,

\footnotetext{
${ }^{11}$ Ver: (OLIVEIRA, 2012, 2018).
} 
partido que fora redenominado assim com a dissolução da ARENA, partido governista durante o período autoritário.

Os últimos anos dos militares no poder, fora marcado por uma crise inflacionária, após a crise do petróleo em 1974, e pelo endividamento externo causado pelo plano nacional de desenvolvimento dos militares, sendo este pano de fundo da transição (KINZO, 2001, p. 4). Logo, a permanência dos militares no poder se tornara insustentável.

Nesse sentido, o processo de aberturas democráticas, ao que sugere a literatura, se deu num período de transição, marcado, também, e, fundamentalmente, pelo protagonismo de lideranças civis que representavam setores populares como, por exemplo, os movimentos sindicais e o Partido dos Trabalhadores (PT). Por outro lado, setores organizados da Ordem dos Advogados do Brasil - OAB e diversas outras organizações, também se uniram em prol do processo de redemocratização. Os movimentos sindicais e outros movimentos e organizações da sociedade civil tiveram um protagonismo fundamental no que tange as pressões feitas nas ruas e nos circuitos do poder real, porém, em menor força, nos espaços institucionalizados dos partidos políticos, haja vista que tais instituições eram controladas, em grande medida, por agentes do establishment. O MDB assumia a oposição, em termos de institucionalização partidária ao regime, embora sendo partido controlado por famílias do poder. Para tanto, mesmo observando as forças externas e internas em disputa no campo política, observa-se que os militares e os civis representantes das tradicionais famílias políticas regionais, seguiam na articulação da dinâmica da transição.

Com a instauração do Ato Institucional $\mathrm{N}^{\circ}$ 2, que extinguiu o pluripartidarismo e estabelecia as eleições indiretas para presidente que fora realizada pelo Congresso Nacional em 1965, que foi criado o Movimento Democrático Brasileiro (MDB) como o partido oposicionista ao governo. Em 1980 quando o Congresso decide extinguir o bipartidarismo o MDB passa a se Chamar Partido do Movimento Democrático Brasileiro (PMDB) e vê-se crescer ao longo dos anos seguintes, porém, com uma perda relativa na composição dos seus quadros, o que em linhas gerais não constituiu um problema (RODRIGUES 2009).

Contudo, mesmo com uma perda relativa de tamanho, o que não poderia ser diferente devido à retomada do pluripartidarismo, o PMDB foi um partido de extrema importância para os governos subsequentes, sempre com atores em posições estratégicas 
nas bases governistas em decorrência de sua amplitude dentro do Congresso Nacional e seu alcance nos estados e municípios. Este último aspecto, por sua vez, possibilitou um efeito peculiar produzido pelas próprias ambiguidades no partido e, mais especificamente, pela característica do federalismo brasileiro e pela autonomia dada aos partidos no que tange a sua organização pela Constituição de 1988 (NOVAES 1994). Nesse sentido, os diretórios estaduais possuíam poder relativo tornando-se imprescindível o controle de oligarquias locais, devido o alcance de sua influência política e poder econômico.

Nobre (2013) apud Monteiro (2017, p.39) destaca como nesse momento de transição o PMDB estimulou um modo de fazer política denominada de "peemedebismo", que em linhas gerais, tratava-se de um conjunto de estratégias de ocupar cargos na alta hierarquia do Estado, a partir da constituição de redes para manter ou facilitar o acesso a estes mesmos cargos. Aliás, esta foi uma característica do PMDB durante as ultimas décadas e governos, sendo ele sempre da base governista.

(...) o PMDB tornou-se, no período de transição, o símbolo das aberturas democráticas. Um partido que se constituiria a partir da heterogeneidade de agentes políticos das mais diversas linhagens políticas e com verdadeiros caciques regionais. Um partido que se caracterizaria pelo fisiologismo e que, portanto, tem como característica a permanência no poder. (Idem. p, 38)

Deste modo, o PMDB se constituiu como um partido que, comparado aos demais do nosso fragmentado sistema partidário, teve e tem ainda muita força em todo território nacional em graus variados.

O Partido da Frente Liberal, por sua vez, foi formado por dissidentes do PDS que formaram a Frente Liberal, instituindo-a como partido no ano 1986, sendo refundado em 2007 como Democratas. Assim como o PMDB, o PFL foi um importante partido de governo, principalmente nos governos de Fernando Henrique Cardoso. Contudo, diferentemente do PMDB, vira oposição com a eleição de Luiz Inácio Lula da Silva. Para Ribeiro (2014) este foi o fator da decadência do PFL. A ascensão do "lulismo" e do Partido dos Trabalhadores no Nordeste fez o PFL perder seu principal reduto eleitoral.

Segundo Singer (2012, p.36), o "lulismo" se caracterizou como uma revolução passiva e uma política de massa. Se partirmos do pressuposto da forte tradição personalista que caracterizava os subsistemas partidários do Nordeste, a figura do presidente Lula assumiu, por meio das políticas sociais realizadas em seus governos, o posto de liderança e unificou uma massa de eleitores antes subordinados aos políticos 
tradicionais por distribuição de recursos escassos. Aliás, o estudo de Vasconcelos (2017) que correspondeu a sua tese de doutoramento, explicita a longevidade de ciclos políticos no Nordeste e uma tradição governista e fidelidade aos partidos que lá estavam havendo uma modificação não muito significativa nesta dinâmica com a eleição de Lula.

Destarte, a presença de representantes de tradicionais elites e famílias políticas ${ }^{12}$ da classe dirigente nordestina nesses partidos é base em seus processos de formação. Em todos os estados do Nordeste, desde a redemocratização, a força destes partidos é indiscutível, havendo uma leve discrepância quando se observa cada subsistema, todavia, o protagonismo é o mesmo. Monteiro (2017) aponta como no Estado da Paraíba, antes da década de 1980, os principais partidos (UDN e PDS), eram controlados pelas oligarquias locais e que nos anos de ditadura alocaram-se na Arena e no MDB. Em tese, após a abertura democrática, o fenômeno permanece sendo o lócus de reprodução destas elites o PMDB e o PDS/PFL.

As redes de relações estabelecidas entre as famílias políticas continuariam sendo uma das características do fazer político no Estado. Não se tratava de uma característica do modo de fazer política na primeira república, mas de estratégias utilizadas por essas famílias. Modos de agir e de pensar a política que se instauraram nos corpos e nas mentes dos agentes políticos. Os agentes se apropriam e se inserem nos partidos, quase sempre, com o intuito de alcançar os interesses do "grupo familiar" que historicamente participaram no aparelho de Estado, exercendo funções públicas, e pertenceram ao polo dominante das disputas políticas. (Idem. p. 41-42)

Se observarmos as eleições para governador e para as prefeituras das capitais dos estados nordestinos, a partir de 1986 até os dias atuais, podemos ter uma dimensão sobre os partidos que se sobressaem nas disputas e sobre os grupos políticos que os comandam. Vasconcelos (2017) traça a história das disputas eleitorais em nível estadual e municipal em cinco estados do Nordeste, afirmando que a política nordestina é permeada pela longevidade de ciclos políticos que correspondem na baixa competitividade eleitoral alicerçada sobre o atraso econômico, político e social que a literatura especializada do campo expõe sobre essa região.

A história política nordestina é caracterizada pela dominância de ciclos políticos característicos de cada estado. Nesse sentido, é necessária a reflexão sobre os efeitos causados pela permanência no poder de

\footnotetext{
${ }^{12}$ Famílias políticas são aquelas que ocupam cargos públicos há mais de meio século. (MONTEIRO 2017.
} p.172) 
Revista NEP - Núcleo de Estudos Paranaenses, Curitiba, v. 5, n. 2, dez. 2019 Dossiê Oligarquias do Nordeste no Brasil

lideranças políticos (pessoas, 43 partidos ou grupos) por tempos consideráveis que excedem a um mandato e conduzem ao reconhecimento de hegemonia em determinados espaços políticos. Assim podemos citar como exemplos de ciclos políticos: a Era Tasso, no Ceará; o Carlismo, na Bahia; os Sarney, no Maranhão, etc. (Idem. p. 42-43)

Os quadros políticos nas disputas eleitorais desde 1985 até os dias atuais, de uma forma ou de outra, apontam para o protagonismo destes partidos mesmo havendo certo nível de competitividade e a participação de outros partidos que ao longo dos anos assumiram um protagonismo nas disputas dos subsistemas do Nordeste como o PT, PSB, PSDB, e o PDT.

O quadro 1, abaixo, apresenta, de forma sintética, algumas das principais representações dos quadros políticos dos dois partidos apresentados ao longo do período proposto.

Quadro 1- Alguns representantes nos quadros políticos do PMDB e PFL.

\begin{tabular}{|c|c|c|}
\hline & PMDB & PFL \\
\hline Alagoas & $\begin{array}{l}\text { Representado por parte do setor } \\
\text { sucroalcooleiro do Estado, com } \\
\text { destaque para o protagonismo } \\
\text { dos Senadores Renan Calheiros; } \\
\text { Teotônio Vilela; e do ex- } \\
\text { presidente Fernando Collor de } \\
\text { Mello }^{13} \text {. }\end{array}$ & $\begin{array}{l}\text { Representado por parte do setor } \\
\text { sucroalcooleiro do Estado, tendo } \\
\text { maior destaque o senador } \\
\text { Guilherme Palmeira; e Divaldo } \\
\text { Suruagy. }\end{array}$ \\
\hline Bahia & $\begin{array}{l}\text { Apesar do ostracismo em } \\
\text { detrimento da força primeiro do } \\
\text { carlismo e, posteriormente, do } \\
\text { petismo, o PMDB tinha uma boa } \\
\text { base no Estado. Despontam como } \\
\text { principais lideranças o ex- } \\
\text { governador Waldir Pires }{ }^{14} \text {, e o }\end{array}$ & $\begin{array}{l}\text { Lugar de maior força do PFL no } \\
\text { Nordeste, representado pelo ex- } \\
\text { governador e Ministro, líder do } \\
\text { carlismo, Antônio } \\
\begin{array}{l}\text { Magalhães (ACM) e } \\
\text { principais aliados. }\end{array}\end{array}$ \\
\hline
\end{tabular}

\footnotetext{
${ }^{13}$ Fernando Afonso Collor de Melo, nascido no Rio de Janeiro, é um exímio filho das elites. Seu pai, Arnon de Melo, foi governador e senador por Alagoas. Seu avô materno, Lindolfo Collor foi deputado federal pelo Rio Grande do Sul e Ministro do trabalho, indústria e comércio durante o governo provisório de Getúlio Vargas. Seu avô paterno, Manuel Afonso de Melo, era um rico proprietário de engenho em Alagoas. A família Collor de Melo é uma das famílias mais tradicionais da região Nordeste, proprietária de diversos empreendimentos com destaque à propriedade de redes de televisão e rádio, além de mídia impressa. Disponível em: http://www.fgv.br/cpdoc/acervo/dicionarios/verbete-biografico/collor-fernando

${ }^{14}$ Francisco Waldir Pires nasceu em Acajutiba-BA. Filho de José Pires de Sousa e de Lucíola Figueiredo Pires de Sousa. Foi Dep. Fed. E governador pela Bahia, e ocupou os ministérios de previdência e assistência social no governo José Sarney e os de controle e transparência e defesa respectivamente nos dois governos Lula.
} 


\begin{tabular}{|c|c|c|}
\hline & $\begin{array}{lll}\text { ex-ministro } & \text { Geddel } & \text { Vieira } \\
\text { Lima. } & & \\
\end{array}$ & \\
\hline Pernambuco & $\begin{array}{l}\text { De tradição política famílista o } \\
\text { PMDB foi lócus de } \\
\text { representantes de famílias } \\
\text { tradicionais da política neste } \\
\text { estado, destaque para Jarbas } \\
\text { Vasconcelos, Marcos de Barros } \\
\text { Freire }^{16} \text { e o próprio Miguel } \\
\text { Arraes de Alencar. }\end{array}$ & $\begin{array}{l}\text { O PFL em Pernambuco teve } \\
\text { como representantes em seus } \\
\text { quadros o ex-senador Marco } \\
\text { Maciel }^{17} \text {; Roberto Magalhães; } \\
\text { Mendoça Filho, Gustavo Krause } \\
\text { entre outros. }\end{array}$ \\
\hline Paraíba & $\begin{array}{l}\text { Partido forte no Estado, teve } \\
\text { como representantes em seus } \\
\text { quadros personagens como } \\
\text { Ronaldo Cunha Lima; Raniere } \\
\text { Paulino; Nabor Wanderley; José } \\
\text { Maranhão; Ruy Carneiro e } \\
\text { Veneziano Vital do Rêgo. }{ }^{18}\end{array}$ & $\begin{array}{l}\text { O PFL permaneceu no } \\
\text { ostracismo diante da força do } \\
\text { PMDB neste estado. A } \\
\text { representação de maior destaque } \\
\text { foi o ex-governador Wilson } \\
\text { Braga. }\end{array}$ \\
\hline Rio Grande do Norte & $\begin{array}{l}\text { O partido foi lócus de reprodução } \\
\text { da oligarquia Alves, que teve } \\
\text { entre seus representantes } \\
\text { Garibaldi Alves Filho e Henrique } \\
\text { Eduardo Alves. }\end{array}$ & $\begin{array}{l}\text { Nos quadros representativos no } \\
\text { RN destacam-se representantes } \\
\text { de oligarquias tradicionais como } \\
\text { José Agripino Maia; Rosalba } \\
\text { Ciarlini Rosado. }\end{array}$ \\
\hline Ceará & $\begin{array}{l}\text { Ciclo dos industriais do Ceará. } \\
\text { Representado pelo ex- } \\
\text { governador Tasso Jereissati; Os } \\
\text { irmãos Ferreira Gomes e Juraci } \\
\text { Magalhães. }\end{array}$ & $\begin{array}{l}\text { Representantes do "pacto dos } \\
\text { coronéis" herdeiros da tradição } \\
\text { arenista no Ceará, tendo como } \\
\text { principais representantes José } \\
\text { Adauto Bezerra } 19 \text { e Paulo de } \\
\text { Tarso Lustosa da Costa. }\end{array}$ \\
\hline
\end{tabular}

${ }^{15}$ Geddel Quadros Vieira Lima (Salvador 1959) foi dep. fed. pela Bahia e Ministro da Integração nacional. Filho de Marluce Quadros Vieira Lima e Afrísio de Sousa Vieira Lima, que foi vereador de Itaquara-BA e secretário estadual de segurança pública da Bahia no governo de Nilo Coelho.

${ }^{16}$ Marcos de Barros Freire nasceu em Recife no dia 5 de setembro de 1931, filho de Luís de Barros Freire, físico e professor catedrático da Escola Politécnica de Recife, e de Branca Palmira Freire. Seu tio Antônio de Barros Carvalho foi deputado federal por Pernambuco (1947 e 1951-1959), senador (1959-1960, 19611966) e ministro da Agricultura (1960-1961). Disponível em: http://www.fgv.br/cpdoc/acervo/dicionarios/verbete-biografico/marcos-de-barros-freire

${ }^{17}$ Dos nove filhos do ex-deputado federal José do Rego Maciel foi o que conseguiu ter mais sucesso na política trilhando os passos do pai, formado em direito assim como ele, Marco Maciel ocupou diversos cargos ao longo de sua trajetória, sendo o primeiro o de Deputado estadual por Pernambuco aos 26 anos de idade em 1966, foi também Deputado Federal, Senador, Governador de Pernambuco em 1978 (nomeado), e Vice-Presidente da República por duas vezes na Chapa de Fernando Henrique Cardoso (PSDB). A família de Marco Maciel descende do comerciante português José do Rêgo Couto, avô de Frederico Alves do Rêgo Maciel, que foi casado com Maria Eulália Falcão e que são avós de Marco Maciel. "Inúmeras famílias ilustres do Sertão e do Agreste de Pernambuco, descendem do português José do Rêgo Couto, e tanto é verdade, que uma série de Magistrados, Médicos, Advogados, Comerciantes e Políticos, estão ligados direta ou indiretamente ao citado luzitano (...) houve grande entrelaçamento entre as famílias Rêgo Couto, Maciel, Cordeiro, Oliveira Melo, Muniz Falcão, Marinho, Araújo, Magalhães, Cavalcanti, Amaral, Carvalho, Campos, Tavares e Santos; todavia, originados de portuguêses radicados no Brejo da Madre de Deus durante os Séculos XVIII e XIX, e seus descendentes transferidos para Cimbres, Pesqueira Garanhuns, enfim, para todo o Agreste e Sertão da então Província de Pernambuco". (Disponível em: https://blogdojvl.blogspot.com/2017/09/o-generoso-alipio-magalhaes-o.html)

${ }^{18}$ Cf. MONTEIRO, 2017.

${ }^{19}$ José Adauto Bezerra nasceu em Juazeiro do Norte (CE) no dia 3 de julho de 1926, filho de José Bezerra de Meneses e de Maria Amélia Bezerra de Meneses. Sua família, radicada no sul do Ceará desde o século XVIII, tornou-se a mais rica de Juazeiro do Norte e uma das mais poderosas do estado, tendo interesses em 


\begin{tabular}{|c|c|c|}
\hline Piauí & $\begin{array}{l}\text { Representantes da oligarquia } \\
\text { Portella, sendo o principal } \\
\text { representante Lucídio Portella, } \\
\text { além dele destacam-se Heráclito } \\
\text { Fortes, Wall Ferraz e Alberto } \\
\text { Silva. }\end{array}$ & $\begin{array}{l}\text { Partido da oligarquia Almendra } \\
\text { Freitas, representados pelo ex- } \\
\text { governador Hugo Napoleão, } \\
\text { Freitas Neto, Atila Lira e Ciro } \\
\text { Nogueira }^{20} \text {. }\end{array}$ \\
\hline Maranhão & $\begin{array}{l}\text { Representado por uma das } \\
\text { maiores lideranças políticas do } \\
\text { PMDB, o ex-presidente José } \\
\text { Sarney. }\end{array}$ & $\begin{array}{l}\text { O PFL era no Maranhão um } \\
\text { partido comandado por aliados da } \\
\text { oligarquia Sarney, como } \\
\text { representantes em seus quadros } \\
\text { estavam lideranças como } \\
\text { Roseana Sarney; Edison Lobão e } \\
\text { Alexandre Costa. }\end{array}$ \\
\hline
\end{tabular}

Fonte: elaborada pelos autores.

Conforme é visto no quadro 1, é significativa a presença de representantes de tradicionais famílias e oligarquias políticas do Nordeste. Estes grupos destacam-se não somente pela participação no mercado de representação política, mas também pela atuação e domínio em setores do campo empresarial como, por exemplo, nos sistemas de comunicação, controlando rádios e redes de televisão, no ramo imobiliário e de construção civil, no setor sucroalcooleiro, no setor de serviços com destaque para a educação e saúde, entre outros diversos empreendimentos (MONTEIRO, 2017); VASCONCELOS, 2017).

Nestes termos, os partidos tornam-se também um lugar de empreendimento realizado, fundamentalmente, em família. No Maranhão, por exemplo, é muito significativa a relação dos partidos com a principal oligarquia local. Apesar de ser um representante histórico do PMDB e atuar politicamente no Amapá, José Sarney teve ao longo das décadas de 1980 e 1990 importantes aliados tanto dentro do PMDB quanto no PFL, partido pelo qual foram eleitos os governadores Edison Lobão e Roseana Sarney.

Se o fenômeno Sarney representa a longevidade de um ciclo político e o controle partidário no estado do Maranhão, é na Bahia que temos a representação não só de

vários setores da economia. Fizeram também carreira política seu irmão gêmeo, Humberto Bezerra, deputado federal pelo Ceará de 1967 a 1971 e em 1975, e o irmão mais novo, Orlando, deputado federal de 1983 a 1995. Disponível em: http://www.fgv.br/cpdoc/acervo/dicionarios/verbete-biografico/joseadauto-bezerra

${ }^{20}$ Ciro Nogueira Lima Filho nasceu em Teresina no dia 21 de novembro de 1968, filho de Ciro Nogueira Lima e de Eliane e Silva Nogueira Lima. Seu pai foi deputado federal pelo Piauí de 1983 a 1987 e de 1991 a 1995. Seu tio Etevaldo Nogueira Lima foi constituinte de 1987 a 1988 e deputado federal pelo Ceará de 1987 a 1995. Disponível em: http://www.fgv.br/cpdoc/acervo/dicionarios/verbete-biografico/cironogueira-lima-filho 
longevidade política e controle partidário, mas de uma forma de se operar neste campo denominada de "Carlismo".

Durante cerca de vinte anos os partidos de direita, liderados pelo antigo PFL, hoje DEM, estabeleceram vasta hegemonia no estado. Tendo o ex-governador ACM como principal liderança de uma forma de fazer política caracterizada por práticas carismáticas e autocráticas (...). $\mathrm{O}$ carlismo deve ser pensado não apenas como um grupo político, mas como uma "política", ou um modo de fazer política que mescla modernização econômica e conservadorismo político na forma de governar. (VASCONCELOS, 2017, p. 82-83)

Aliás, havia uma relação de proximidade entre Antônio Carlos Magalhães e José Sarney. ACM foi um ferrenho oposicionista à candidatura de Paulo Maluf à presidência pelo PDS, na ocasião, após o partido efetivar a candidatura de Maluf, ACM declarou apoio a Tancredo Neves e a Aliança Democrática, sendo nomeado, posteriormente, Ministro das Comunicações no governo Sarney, sendo ambos os protagonistas do episódio que ficou conhecido como "farra das concessões".

Como Ministro das Comunicações e figurado entre os políticos mais influentes do Governo Sarney, ACM aproveitou para dar diversas concessões de televisão e rádio a seus aliados na Bahia. Além disso, Antônio Carlos Magalhães e sua família controlavam, na época, todas as filiadas da Rede Globo no estado e o Jornal Correio da Bahia. O controle dos veículos de comunicação baianos por parte do carlismo rendeu diversas matérias que visavam transmitir uma imagem positiva de ACM. (Idem, p. 96)

O controle dos veículos de comunicação é uma característica marcante das oligarquias e famílias políticas que compõem a classe dirigente não só, mas especificamente no Nordeste. A mídia, colonizada pelo dinheiro e pela influência destes grupos políticos, fomentam uma linguagem na "opinião pública" que possibilita legitimar, perante a população, figuras que estejam sob a tutela de padrinhos políticos e que irão dar continuidade aos seus ciclos de dominação política. Sem exceção, em todos os estados do Nordeste há o controle de veículos de comunicação por parte de grupos políticos que não necessariamente representam oligarquias que remontam aos tempos dos coronéis. No Ceará, por exemplo, o período ditatorial serviu de base à ascensão do grupo de empresários do Centro Industrial do Ceará (CIC), figurando como principais representantes o ex-governador Tasso Jereissati e os irmãos Ferreira Gomes.

No Ceará, a ascensão de Tasso Jereissati ao governo do Estado em 1986, deu início à nomeada "era das mudanças", contraposta ao que foi consagrado como "era dos coronéis". A simbólica da modernização da 
Revista NEP - Núcleo de Estudos Paranaenses, Curitiba, v. 5, n. 2, dez. 2019

política cearense, efetivada por um personagem jovem, assentava-se em um imaginário político de racionalidade da gestão empresarial, que tinha como contraponto a "política clientelista" dos coronéis. O ciclo político inaugurado em 1986 ganhou nomeações que não deixam dúvidas sobre a centralidade atribuída ao seu "fundador", ("tassismo", "era Tasso"). (CARVALHO, 2008, p.23 apud. VASCONCELOS, 2017, p. 45)

Se no caso do Maranhão e da Bahia a ditadura elevou tradicionais oligarquias, no Ceará se consolidou o poder de uma nova elite política. O grupo de empresários do CIC representados pelo ex-governador Tasso Jereissati figurou como principal grupo na política estadual. O PFL no Ceará, que alocava representantes das velhas oligarquias, ficou no ostracismo no cenário político cearense no período pós-redemocratização. O grupo tassista de início filiado ao PMDB se consolida, de fato, nos quadros do PSDB. Com o enfraquecimento do grupo tassista, o protagonismo passa à aliança feita entre PT e PSB que tinha como cabeça os irmãos Ciro e Cid Gomes que já foram aliados do grupo tassista. Nestes termos, no Ceará, desde a primeira eleição de Tasso Jereissati ao governo do estado, não houve o surgimento de novas lideranças, mas "uma dança das cadeiras" entre velhas representações que ora já foram aliados.

Em contraposição, os subsistemas partidários do Piauí, Rio Grande do Norte e Paraíba - mesmo depois da popularidade adquirida pelo PT com a eleição de Lula em 2002 e novamente em 2006, consolidando a região como seu reduto eleitoral -, permaneceu a força política de velhas oligarquias que inclusive, em alguns casos, aliaramse ao Partido dos trabalhadores.

O subsistema partidário do Piauí tem uma forte tradição "familista". Vasconcelos (2017) destaca que nos anos do regime militar a política Piauiense era dominada pelas famílias Almendra Freitas e Portella Nunes. Contudo, nos anos seguintes ao fim do período militar com uma maior institucionalização do sistema político-eleitoral, houve pouca alteração no que concernem as lideranças políticas do Estado.

Mesmo após a redemocratização de 1988, o que se observou no subsistema partidário piauiense foi a presença de herdeiros políticos e familiares das principais famílias políticas do estado, que utilizaram o poder público para a sobrevivência e reprodução de seus grupos políticos, sendo assim um sistema marcado por características conservadoras e excludentes. (VASCONCELOS, 2017, p. 127)

Representantes das duas famílias atuavam nos quadros partidários da ARENA durante a ditadura e, posteriormente, no PDS. Porém, divergências internas causaram o 
rompimento entre os grupos encabeçados por Lucídio Portella, herdeiro do ex-governador e senador Petrônio Portella, e Hugo Napoleão, primo do ex-prefeito de Teresina Antônio de Almendra Freitas, mudando significativamente as disputas nos anos seguintes. Hugo Napoleão foi responsável pela criação do PFL no estado. O PMDB, por sua vez, era o Partido do ex-governador Alberto Silva que, devido ao racha no PDS, teve apoio de Lucídio Portella contra o candidato Atila Lira (PFL) nas eleições para governador em 1986. Entretanto, a aliança entre as famílias Portella e Almendra Freitas é reatada nas eleições de 1990, tendo a chapa formada pelo primo de Hugo Napoleão, Freitas Neto (PFL), candidato à governador e o genro de Lucídio Portella, Guilherme Melo (PDS), como vice.

No Rio Grande do Norte duas famílias dominam e aparelham a política e os partidos no estado há décadas. As famílias Alves e Mariz-Maia são símbolos da tradição familiar que perpassa a história política do Rio Grande do Norte, do Nordeste e do Brasil, estendendo suas redes de influência não somente no estado potiguar. A longevidade política destas famílias e seus representantes resistem até os dias atuais onde o PT da governadora Fátima Bezerra tem se sobressaído sobre as demais siglas nas disputas eleitorais neste estado. No entanto, conforme já destacamos, partimos do pressuposto que as siglas partidárias sob estas circunstâncias nada mais são que o aparelho que estas famílias possuem para selecionar os representantes que elas bem entenderem. Foi assim com o PDS e a UDN antes da ditadura; com o MDB e a ARENA durante o período autoritário; e com o PMDB e PFL pós-redemocratização.

\begin{abstract}
Apesar dos desdobramentos e mudanças de nomes das legendas ao longo de décadas, no caso do Rio Grande do Norte, ambas permanecem sob o controle dos mesmos grupos familiares, Alves e Maia, que igualmente continuam a polarizar a disputa local, em amplitude estadual, frustrando ao longo do tempo, com base em articulações políticas locais e suportes nacionais, as diversas tentativas de outros grupos de se estabelecerem como força política autônoma e independente. (CARVALHO, 2018, p. 51)
\end{abstract}

Aliás, as diversas redes da família Maia lhe propuseram ter representantes em outros estados da federação como no Rio de Janeiro e na Paraíba, estado vizinho, estendendo seu poder político e influência. 
Revista NEP - Núcleo de Estudos Paranaenses, Curitiba, v. 5, n. 2, dez. 2019

(...) se constituindo em uma das maiores oligarquias da Região Nordeste. Oligarquia que ultrapassou as fronteiras do Estado da Paraíba, por meio dos mais variados ramos parentais. (...) Trata-se de uma família que tem ocupado as instâncias de poder de vários Estados da federação, com destaque para os Estados da Paraíba, Rio Grande do Norte e Rio de Janeiro. Estados que tiveram a frente do executivo, herdeiros dos coronéis que controlavam e dominavam as terras da Paraíba. (MONTEIRO, 2017, p. 238)

Além da presença da família Maia, a Paraíba é reduto de diversas famílias políticas, algumas que se configuram como sinônimo de poder há décadas no Estado. Monteiro (2017), em seu trabalho de tese, expõe cerca de vinte famílias políticas que atuam no estado. No entanto, no que tange aos partidos observados neste trabalho, os quadros foram variados tendo protagonismo o PMDB que, após a ditadura, teve cinco governadores, entre eles estão representantes de famílias tradicionais da classe dirigente do Estado como, por exemplo, Antônio Mariz; Ronaldo Cunha Lima e José Maranhão.

Vasconcelos (2017) aponta que as disputas no Estado de Alagoas são dinamizadas pelas elites usineiras do estado que, quando eles próprios não saem como candidatos, lançam seus representantes. Segundo ela, não houve no período de redemocratização o surgimento de novas lideranças políticas, mas o reordenamento de elites tradicionais que, como em outros estados, utilizam das legendas para selecionar seus representantes a partir de seus critérios. Deste modo, tanto o PMDB quanto o PFL, foram redutos e lugar de reprodução destes grupos. Deste modo, personagens como Divaldo Suruagy e Renan Calheiros, foram iniciados na política por lideranças como Rui Palmeira ${ }^{21}$ e João Lyra ${ }^{22}$ respectivamente.

\footnotetext{
${ }^{21}$ Rui Soares Palmeira nasceu em São Miguel dos Campos (AL) no dia 2 de março de 1910, filho de Miguel Soares Palmeira e de Teresa Ferro Soares Palmeira. Em sua família destacou-se João Lins Vieira Cansansão de Sinimbu, visconde de Sinimbu, que foi presidente de Alagoas, Sergipe, Rio Grande do Sul e Bahia, deputado-geral em 1842 e 1853, senador por Alagoas em 1857, ministro dos Estrangeiros em 1859 e 1878, ministro da Justiça em 1862, ministro da Agricultura em 1862 e 1878 e presidente do Conselho de Ministros em 1878. Disponível em: http://www.fgv.br/cpdoc/acervo/dicionarios/verbete-biografico/rui-soarespalmeira

${ }^{22}$ João José Pereira de Lyra nasceu em Recife no dia 17 de junho de 1931. Filho de Salvador Pereira de Lyra e de Maria da Conceição Diniz Pereira de Lyra. Seu irmão Carlos Lyra foi senador por Alagoas de 1981 a 1987.Bacharelou-se em ciências jurídicas e sociais na Faculdade de Direito de Alagoas em 1960. Empresário do setor sucroalcooleiro, fundou o grupo João Lyra e presidiu a Laginha Agroindústria S.A., a matriz Usina Laginha, em União dos Palmares (AL). Disponível em: http://www.fgv.br/cpdoc/acervo/dicionarios/verbete-biografico/lira-joao
} 
Revista NEP - Núcleo de Estudos Paranaenses, Curitiba, v. 5, n. 2, dez. 2019

No Estado de Pernambuco, berço de tradicionais famílias da economia canavieira, o PFL e o PMDB tiveram protagonismo após o fim do regime militar. O ex-governador e prefeito do Recife Miguel Arraes de Alencar, um dos principais símbolos da luta pela retomada da democracia foi um importante partidário do MDB e do PMDB. Contudo, divergências internas dentro do partido foram desgastando sua relação com o também exprefeito e governador do Recife Jarbas Vasconcelos que, na ocasião das eleições para governador para 1986 em oposição à Arraes, forma uma aliança as pressas para sua candidatura com o PDS. De volta ao PMDB e com Arraes já no PSB, Jarbas, com o domínio sobre o PMDB, forma uma aliança de oposição com o PFL de Marco Maciel e Roberto Magalhães contra a principal liderança política da época no estado, acumulando algumas vitorias na capital pernambucana.

\section{Considerações}

As problematizações realizadas por meio deste trabalho surgem da reflexão sobre a atuação dos partidos brasileiros no que tange aos critérios de seleção dos seus representantes. A utilização da região Nordeste como lócus de nossa pesquisa não foi por entendermos que o fenômeno da presença de oligarquias e longos ciclos políticos ocorrem, fundamentalmente, na região, pelo contrário, trata-se de um fenômeno que no Brasil perpassa fronteiras e situa-se sobre contextos divergentes no que concerne aos processos de desenvolvimento local.

A escolha da região Nordeste nos pareceu pertinente em virtude da importância que os partidos por nós observados no período proposto tinham na região e como estes foram fundamentais para o processo de retomada da democracia sobre os moldes que expomos ao longo do texto. Deste modo, compreendemos como fundamental às análises sobre partidos e representação que sejam considerados os aspectos referentes à composição social das legendas e a quem de fato elas representam.

Pudemos evidenciar ao longo do trabalho que, apesar de um conjunto de medidas de modernização econômica e política pelo reordenamento do aparelho burocrático e pela institucionalização dos partidos, longos ciclos políticos e forte presença de elites e famílias políticas representantes da classe dirigente regional ainda marcam forte presença sobre os processos decisórios da política local em graus variados, mas, ainda sim, de 
forma decisiva, impedindo o surgimento de novas lideranças e reproduzindo seu poder, prestígio e patrimônio.

\section{Referências}

CODATO, Adriano Nervo. Uma História Política da Transição Brasileira: da ditadura militar à democracia. Revista de sociologia e política. Curitiba, 25, p. 83-106, Nov. 2015.

BOURDIEU, Pierre. O Poder Simbólico. Bertrand, São Paulo, 1989, p.163-207.

CARREIRÃO, Yan de Souza. KINZO, Maria D'Alva G. Partidos políticos, preferência partidária e decisão eleitoral no Brasil (1989/2002). DADOS - Revista de Ciências Sociais, Rio de Janeiro, v. 47, n.1 2004, p. 131-168.

MONTEIRO, José Marciano. Política como negócio de família: para uma sociologia políticas das elites e do poder político-familiar. São Paulo, Editora LiberArs, 2017.

SINGER, André Vitor. Os sentidos do lulismo: reforma gradual e pacto conservador. $1^{\mathrm{a}} \mathrm{Ed}$. São Paulo, Companhia das Letras 2012.

VASCONCELOS, Bruna Karoline. Competição e ciclos políticos nos subsistemas partidários do Nordeste: um estudo de caso sobre CE, AL, BA, MA e PI. Tese (Doutorado), Universidade Estadual de Campinas - Instituto de Filosofia e Ciências Humanas, Campinas 2017.

FURTADO, Celso. Formação Econômica do Brasil. 33. Ed. São Paulo, Companhia Editora Nacional, 2004.

BERNARDES, Denis de Mendonça. Notas sobre a formação social do Nordeste. Lua Nova, São Paulo, 71, p. 41-79, 2007.

KINZO, Maria D’Alva G. A democratização brasileira: um balanço do processo político desde a transição. Em perspectiva, São Paulo, 15 (4), 2001.

NOVAES, Carlos Alberto Marques. Dinâmica Institucional da Representação: Individualismo e Partidos na Câmara dos Deputados. Novos Estudos, n 38, março, 1994.

OLIVEIRA, Ricardo Costa (Org.). Na teia do nepotismo: sociologia política das relações de parentesco e poder político no Paraná e no Brasil. Curitiba: Ed. Insigth, 2012.

Família importa e explica: instituições políticas e parentesco no Brasil. São Paulo, LiberArs, 2018. 
N E P Revista NEP - Núcleo de Estudos Paranaenses, Curitiba, v. 5, n. 2, dez. 2019 Dossiê Oligarquias do Nordeste no Brasil ISSN: $2447-5548$

RIBEIRO, Ricardo Luiz Mendes. Decadência longe do poder: refundação e crise do PFL. Revista de sociologia e política, v 22, n 49, p. 5-37, mar. 2014.

RODRIGUES, Leôncio Martins. Partidos, Ideologia e Composição Social. Biblioteca virtual de ciências humanas do Centro Edelstein de Pesquisas Sociais ISBN 978-85-7982-025-0, Rio de Janeiro, 2009. Acessado em: 15/06/2019.

CARVAlHO, Robson Vasconcelos. Família e Política no RN: Alves, Maia e o suporte do Senado. Dissertação (mestrado) Centro de Ciências Humanas, Letras e Artes. Programa de PósGraduação em Ciências Sociais. Natal, RN, 2018.

MACHADO, Audálio José Pontes. A Democracia Representativa no Brasil: problemas e questionamentos. Estação científica (UNIFAP), Macapá, v. 6, n. 1, p. 9-18, jan/abr 2016.

PERISSINOTTO, Renato. As elites políticas: questões de teoria e método. Curitiba, Ibpex, 2009.

Recebido em: 30 out. 2019

Aceito em: 26 nov. 2019 